\title{
Cumulative Clinical Benefits of Biologics in the Treatment of Patients with Moderate-to-Severe Psoriasis over 1 Year: a Network Meta-Analysis
}

\author{
Andrew Blauvelt • Melinda Gooderham • Christopher E. M. Griffiths • \\ April W. Armstrong · Baojin Zhu · Russel Burge · Gaia Gallo • \\ Jiaying Guo · Alyssa Garrelts · Mark Lebwohl
}

Received: December 23, 2021 / Accepted: February 3, 2022 / Published online: February 23, 2022

(C) The Author(s) 2022

\section{ABSTRACT}

Introduction: Both early clinical improvement and long-term maintenance of clinical efficacy of treatments matter to patients with psoriasis. We compared cumulative clinical benefits of treatment with biologics over 1 year based on

Supplementary Information The online version contains supplementary material available at https:// doi.org/10.1007/s13555-022-00690-5.

A. Blauvelt $(\bowtie)$

Oregon Medical Research Center, 9945 SW Locust

St., Suite G, Portland, OR 97223, USA

e-mail: ablauvelt@oregonmedicalresearch.com

M. Gooderham

SKiN Centre for Dermatology, Peterborough, ON, Canada

C. E. M. Griffiths

Dermatology Centre, Salford Royal Hospital, NIHR

Manchester Biomedical Research Centre, University

of Manchester, Manchester, UK

A. W. Armstrong

Keck School of Medicine, University of Southern

California, Los Angeles, CA, USA

B. Zhu · R. Burge · G. Gallo · J. Guo · A. Garrelts Eli Lilly and Company, Indianapolis, IN, USA

R. Burge

University of Cincinnati, Cincinnati, OH, USA

M. Lebwohl

Icahn School of Medicine at Mount Sinai, Mount

Sinai Hospital, New York, NY, USA the area under the curve (AUC) for Psoriasis Area and Severity Index (PASI) 100 and PASI 90 responses in patients with moderate-to-severe psoriasis using a network meta-analysis (NMA). Methods: Published phase 3 randomized, placebo- or active-controlled clinical trial data for biologics approved for the treatment of moderate-to-severe psoriasis were obtained from a systematic literature review up to 30 September 2020. Eighteen clinical trials that included data from baseline to 48 or 52 weeks where AUC could be calculated were included. Data were compared using a fixed-effect model with a separate random-effect baseline model to account for effects of the placebo arm. Cumulative clinical benefit was estimated using the AUC for PASI 100 and PASI 90 responses (complete and almost-complete skin clearance, respectively). Normalized AUC was compared using Bayesian NMA. Cumulative days of response were calculated using normalized AUC and study duration.

Results: Interleukin (IL)-17 and IL-23 inhibitors demonstrated greater cumulative clinical benefits for both PASI 100 and PASI 90 versus IL-12/ 23 and tumor necrosis factor inhibitors. Over 52 weeks, cumulative days with PASI 100 were greatest with ixekizumab [158.7 (95\% credible interval, 147.4, 170.0) days] followed by risankizumab [154.0 (144.9, 163.4) days]; PASI 90 days were greatest with risankizumab [249.3 $(239.5,259.2)$ days] followed by ixekizumab [238.8 (227.1, 250.8) days]. Both ixekizumab 
and risankizumab showed greater cumulative days with PASI 100 or PASI 90 responses versus secukinumab $[117.9(110.7,125.2)$ and 215.5 (208.2, 223.1) days, respectively] and greater cumulative days with PASI 100 versus guselkumab [130.7 (120.5, 140.9) days].

Conclusion: For complete and almost-complete skin clearance, ixekizumab and risankizumab provided the greatest cumulative clinical benefits over 1 year.

Keywords: Area under the curve; Biologics; Cumulative benefit; Ixekizumab; NMA; Psoriasis

\section{Key Summary Points}

\section{Why carry out this study?}

Psoriasis patients value both rapid initial response and the magnitude and durability of long-term clinical response; however, a single measure encompassing both of these is not in common use.

\section{What did the study ask?}

What are the long-term cumulative clinical benefits, assessed as complete and almost-complete skin clearance based on area under the curve, for biologics in the treatment of moderate-to-severe psoriasis?

\section{What was learned from the study?}

In a network meta-analysis assessing area under the curve up to 52 weeks, ixekizumab showed the highest cumulative benefit for complete clearance, followed by risankizumab and other biologics.

For almost-complete clearance, risankizumab showed the highest cumulative benefit, followed by ixekizumab and other biologics.

\section{INTRODUCTION}

Psoriasis is a chronic inflammatory skin disease affecting approximately $2-3 \%$ of the population in the USA [1]. Many biologic therapies that target critical immune-mediated pathways involved in the pathogenesis of psoriasis have been approved, including first-generation tumor necrosis factor (TNF) inhibitors, followed by second-generation biologics such as interleukin (IL)-17, IL-12/23, and IL-23 inhibitors, which elevated the treatment goals for psoriasis. Since there are many biologic choices available to patients and practitioners, comparative data among biologics are needed to help inform treatment decisions.

Both rapid onset of treatment response and the magnitude of sustained response are important to patients affected by psoriasis [2-4]. However, in chronic inflammatory diseases generally, it is also important to assess cumulative disease impact as a marker of overall inflammatory burden; for example, in psoriatic and rheumatoid arthritis, structural damage serves as both an important endpoint and as a surrogate marker of cumulative disease impact. In patients suffering with chronic skin disease, including psoriasis, cumulative life course impairment (CLCI) [5] is a multidimensional tool designed to assess the cumulative burden of skin disease over time. Area under the curve (AUC) for clinical response provides a cumulative assessment of treatment effect, capturing not only the magnitude and speed of onset, but also the maintenance of clinical response over time [6-8]. Indeed, measurements of long-term cumulative benefit may provide more clinically meaningful data than measurements of response at a single timepoint.

Here, we present a network meta-analysis (NMA) comparing the cumulative clinical benefit after 1 year for ten biologic drugs at approved doses for psoriasis, across different classes of inhibitors of key cytokine-mediated pathways, including IL-17 (brodalumab, ixekizumab, secukinumab), IL-12/23 (ustekinumab), IL-23 (guselkumab, risankizumab), and TNF (adalimumab, certolizumab, etanercept, infliximab) based on the achievement of Psoriasis 
Area Severity Index 90\% (PASI 90) and 100\% (PASI 100) improvements. This analysis provides clinically meaningful and relevant comparative data on biologics that should better assist patients and practitioners in their treatment choices for moderate-to-severe psoriasis.

\section{METHODS}

\section{Data Source}

Published phase 3 randomized clinical trial data of biologics given at approved doses for psoriasis were obtained from a systematic literature review as previously described (1990-2018) [6], with the literature search updated through to 30 September 2020 prior to this analysis (Supplementary Materials Fig. 1). The ongoing search is registered at PROSPERO (CRD42021244387). Searches were conducted across the Embase, PubMed, and Cochrane Library electronic databases, and titles and abstracts were reviewed independently by two researchers for inclusion and exclusion. Additional search strategies included conference abstracts, hand searches, clinical trial registries, and health technology websites, updated from the last search. A total of ten biologics were included in the PASI 90 and eight biologics in the PASI 100 analyses. These comprised TNF inhibitors: adalimumab [maintenance dosing $40 \mathrm{mg}$ every 2 weeks (Q2W)], certolizumab (200 mg Q2W, PASI 90 only), etanercept (50 mg biweekly), and infliximab [5 mg/kg every 8 weeks (Q8W), PASI 90 only]; IL-17 antagonists: brodalumab (210 mg Q2W), ixekizumab [80 mg Q2W/every 4 weeks (Q4W)], and secukinumab (300 mg Q4W); IL-23 inhibitors: guselkumab (100 mg Q8W) and risankizumab [150 mg every 12 weeks (Q12W)]; and the IL-12/23 inhibitor ustekinumab (45/90 mg Q12W). AUC 52-week data were not available for tildrakizumab, an IL-23 inhibitor. Studies with rerandomization based on "responder" status without providing the visit-wise response rate on PASI 90/100 through to 52 weeks for each patient were excluded from the analysis; examples of studies excluded on this basis included the ixekizumab UNCOVER-1 [9], UNCOVER-2 [9], and IXORA-R [10] studies, and the tildrakizumab reSURFACE 1 [11] and reSURFACE 2 [11] studies. Phase 2 trials were also excluded from this analysis, as were trials for apremilast, or if AUC could not be calculated from published data available at 4 -week intervals.

The 14 published studies of 18 clinical trials used for data extraction are presented in Table 1. Data extraction was quality checked by a second researcher not involved with the extraction; this quality check included verification of all extracted data against the source document.

This article is based on previously conducted studies and does not contain any new studies with human participants or animals performed by any of the authors.

\section{Outcome Measures}

Total cumulative benefit for ixekizumab and other biologic treatments from Week 0 to 52 at 4-week intervals was estimated using the AUC method as previously described [6-8]. The ratio of AUC to the maximum AUC during the 52 weeks (the normalized AUC) was calculated for all ten biologics. Specifically, the normalized AUC for each treatment was calculated as a proportion of maximum possible AUC. The normalized AUC was compared among biologics using a Bayesian NMA (BNMA) fixed effect model with a separate random effect baseline model $[12,13]$ to obtain stable estimates from the NMA and still account for the effects of the placebo arm on PASI 90/100 (NMA diagrams for PASI 90 and PASI 100, Supplementary Materials Fig. 2). Convergence for all models was assessed using trace plots as modified by Brooks and Gelman [14]. BNMA were performed in JAGS via $\mathrm{R}$ using the R2JAGS package and using $\mathrm{R}$ version 4.03 [15]. Cumulative days of PASI 90/100 responses were calculated by multiplying the normalized AUC for PASI $90 / 100$ by the study duration (in days).

Data on PASI 90/100 used for AUC calculations for active treatments in this analysis were based, wherever possible, on nonresponder imputation (NRI) for missing data. Exceptions were for PASI 90 of one report for certolizumab 
Table 1 Overview of the studies for network meta-analysis

\begin{tabular}{|c|c|c|c|c|c|c|}
\hline \multirow[t]{2}{*}{ Study } & \multirow[t]{2}{*}{ Treatment } & \multirow[t]{2}{*}{$N$} & \multirow[t]{2}{*}{ Last visit (weeks) } & \multirow{2}{*}{$\begin{array}{l}\text { Baseline PASI } \\
\text { Mean } \pm \text { SD }\end{array}$} & \multicolumn{2}{|c|}{$\begin{array}{l}\text { Response rate at last } \\
\text { visit, } \%\end{array}$} \\
\hline & & & & & PASI 100 & PASI 90 \\
\hline \multirow[t]{3}{*}{ AMAGINE-2 [19] } & Placebo & 300 & 12 & $20.4 \pm 8.2$ & - & 3.1 \\
\hline & Brodalumab $210 \mathrm{mg}$ & 189 & 52 & $20.3 \pm 8.3^{\mathrm{a}}$ & 55.8 & 74.9 \\
\hline & Ustekinumab 45/90 mg & 245 & 52 & $20.5 \pm 8.2^{\mathrm{b}}$ & 30.3 & 48.1 \\
\hline \multirow[t]{3}{*}{ AMAGINE-3 [19] } & Placebo & 301 & 12 & $20.1 \pm 8.7$ & - & 1.9 \\
\hline & Brodalumab $210 \mathrm{mg}$ & 194 & 52 & $20.4 \pm 8.3^{c}$ & 52.8 & 73.0 \\
\hline & Ustekinumab $45 / 90 \mathrm{mg}$ & 244 & 52 & $20.1 \pm 8.4^{\mathrm{d}}$ & 28.9 & 50.0 \\
\hline \multirow[t]{2}{*}{ CIMPASI-1 [16] } & Placebo & 51 & 16 & $19.8 \pm 7.5$ & - & 0.4 \\
\hline & Certolizumab & 95 & 48 & $20.1 \pm 8.2$ & - & 42.8 \\
\hline \multirow[t]{2}{*}{ CIMPASI-2 [16] } & Placebo & 49 & 16 & $17.3 \pm 5.3$ & - & 4.5 \\
\hline & Certolizumab & 91 & 48 & $18.4 \pm 5.9$ & - & 59.6 \\
\hline \multirow[t]{2}{*}{ CLARITY [17] } & Secukinumab $300 \mathrm{mg}$ & 550 & 52 & $20.8 \pm 9.0$ & - & 73.1 \\
\hline & Ustekinumab $45 / 90 \mathrm{mg}$ & 552 & 52 & $21.3 \pm 9.2$ & - & 59.8 \\
\hline \multirow[t]{2}{*}{ CLEAR [18] } & Secukinumab $300 \mathrm{mg}$ & 334 & 52 & $21.7 \pm 8.5$ & 46.3 & 76.4 \\
\hline & Ustekinumab 45/90 mg & 335 & 52 & $21.5 \pm 8.1$ & 35.9 & 60.8 \\
\hline \multirow[t]{2}{*}{ ECLIPSE [23] } & Guselkumab 100 mg & 534 & 48 & $20.0 \pm 7.4$ & 58.2 & 84.5 \\
\hline & Secukinumab 300 mg & 514 & 48 & $20.1 \pm 7.6$ & 48.4 & 70.0 \\
\hline \multirow[t]{2}{*}{ ERASURE [20] } & Placebo & 246 & 12 & $21.4 \pm 9.1$ & 0.8 & 1.2 \\
\hline & Secukinumab $300 \mathrm{mg}$ & 245 & 52 & $22.5 \pm 9.2$ & 39.2 & 60.4 \\
\hline \multirow[t]{2}{*}{ EXPRESS [38] } & Placebo & 68 & 24 & $22.8 \pm 8.7$ & - & 1.3 \\
\hline & Infliximab $5 \mathrm{mg} / \mathrm{kg}$ & 281 & 50 & $22.9 \pm 9.3$ & - & 45.2 \\
\hline \multirow[t]{2}{*}{ FEATURE [39] } & Placebo & 59 & 12 & $21.1 \pm 8.5$ & 0 & 0 \\
\hline & Secukinumab $300 \mathrm{mg}$ & 58 & 52 & $20.7 \pm 8.0$ & 43.1 & 62.1 \\
\hline \multirow[t]{3}{*}{ FIXTURE [20] } & Placebo & 324 & 12 & $24.1 \pm 10.5$ & 0 & 1.5 \\
\hline & Etanercept 50 mg BIW & 323 & 52 & $23.2 \pm 9.8$ & 9.9 & 33.1 \\
\hline & Secukinumab $300 \mathrm{mg}$ & 323 & 52 & $23.9 \pm 9.9$ & 36.5 & 65.3 \\
\hline \multirow[t]{2}{*}{ IMMERGE [40] } & Risankizumab 150 mg & 164 & 52 & $19.8 \pm 6.3$ & 66 & 87 \\
\hline & Secukinumab $300 \mathrm{mg}$ & 163 & 52 & $20.1 \pm 8.1$ & 40 & 57 \\
\hline \multirow[t]{2}{*}{ IXORA-S [21] } & Ixekizumab 80 mg Q2W/Q4W & 136 & 52 & $19.9 \pm 8.2$ & 52.2 & 76.5 \\
\hline & Ustekinumab 45/90 mg & 166 & 52 & $19.8 \pm 9.0$ & 35.5 & 59.0 \\
\hline \multirow[t]{2}{*}{ JUNCTURE [41] } & Placebo & 61 & 12 & $19.4 \pm 6.7$ & 0 & 0 \\
\hline & Secukinumab $300 \mathrm{mg}$ & 60 & 52 & $18.9 \pm 6.4$ & 38.3 & 63.3 \\
\hline
\end{tabular}


Table 1 continued

\begin{tabular}{|c|c|c|c|c|c|c|}
\hline \multirow[t]{2}{*}{ Study } & \multirow[t]{2}{*}{ Treatment } & \multirow[t]{2}{*}{$N$} & \multirow[t]{2}{*}{ Last visit (weeks) } & \multirow{2}{*}{$\begin{array}{l}\text { Baseline PASI } \\
\text { Mean } \pm \text { SD }\end{array}$} & \multicolumn{2}{|c|}{$\begin{array}{l}\text { Response rate at last } \\
\text { visit, \% }\end{array}$} \\
\hline & & & & & PASI 100 & PASI 90 \\
\hline \multirow[t]{3}{*}{ ULTIMMA-1 [22] } & Placebo & 102 & 16 & $20.5 \pm 6.7$ & 0 & 4.9 \\
\hline & Risankizumab $150 \mathrm{mg}$ & 304 & 52 & $20.6 \pm 7.7$ & 52.3 & 81.9 \\
\hline & Ustekinumab 45/90 mg & 100 & 52 & $20.1 \pm 6.8$ & 21.0 & 44.0 \\
\hline \multirow[t]{3}{*}{ ULTIMMA-2 [22] } & Placebo & 98 & 16 & $18.9 \pm 7.3$ & 2.0 & 2.0 \\
\hline & Risankizumab $150 \mathrm{mg}$ & 294 & 52 & $20.5 \pm 7.8$ & 59.5 & 80.6 \\
\hline & Ustekinumab 45/90 mg & 99 & 52 & $18.2 \pm 5.9$ & 30.3 & 50.5 \\
\hline \multirow[t]{4}{*}{ UNCOVER-3 [42] } & Placebo & 193 & 12 & $21.1 \pm 8.4$ & 0 & 3.1 \\
\hline & Etanercept 50 mg BIW/ & 382 & 52 & $20.7 \pm 8.2$ & 52.9 & 77.7 \\
\hline & Ixekizumab 80 mg Q4W & & & & & \\
\hline & Ixekizumab 80 mg Q2W/Q4W & 385 & 52 & $20.7 \pm 8.2$ & 54.3 & 74.8 \\
\hline \multirow[t]{3}{*}{ VOYAGE-1 [43] } & Placebo & 174 & 16 & $20.4 \pm 8.7$ & 0.6 & 2.9 \\
\hline & Adalimumab $40 \mathrm{mg}$ & 334 & 48 & $22.4 \pm 9.0$ & 23.4 & 47.9 \\
\hline & Guselkumab $100 \mathrm{mg}$ & 329 & 48 & $22.1 \pm 9.5$ & 47.4 & 76.3 \\
\hline
\end{tabular}

$B I W$ biweekly, $N$ number of patients, $P A S I 75 \geq 75 \%$ improvement in Psoriasis Area and Severity Index, PASI $90 \geq 90 \%$ improvement in Psoriasis Area and Severity Index, PASI 100 100\% improvement in Psoriasis Area and Severity Index, Q2W every 2 weeks, $Q 4 W$ every 4 weeks

Response rates and network meta-analysis for these doses were based on the disposition sample of patients receiving a fixed dose and continuing through 52 weeks, as presented in Supplementary Tables 5 and 6 of Lebwohl et al. [19]

For the AMAGINE studies, baseline PASI data are provided from the published source [19] for the overall population of ${ }^{\mathrm{a}} N=612 ;{ }^{\mathrm{b}} N=610 ;{ }^{\mathrm{c}} N=624 ;{ }^{\mathrm{d}} N=629$

[16] and two reports of studies assessing secukinumab versus ustekinumab [17, 18], and, for PASI 100, one report for secukinumab versus ustekinumab [18], all of which reported endpoints based on multiple imputation for missing data. For the ixekizumab UNCOVER-3 trial, in the present analyses, unpublished data based on the more conservative NRI method were used instead of the previously published modified NRI (mNRI) data. In addition, the placebo arms of the studies typically continued up to Week 12 (or 16); data after Week 12 (or 16) were imputed to Week 52 using last observation carried forward (LOCF). If the original study was of 48-weeks duration, LOCF was used to impute all missing values for PASI 90/100 to 52 weeks.
Sensitivity analysis was conducted by evaluating the normalized AUC at Week 52 for 8 of the 18 studies in the primary analysis that maintained randomization from baseline to 48 or 52 weeks: AMAGINE-2 [19], AMAGINE-3 [19], CLEAR [18], FIXTURE [20], IXORA-S [21], UltIMMa-1 [22], UltIMMa-2 [22], and ECLIPSE [23].

In all analyses, between-drug differences were considered significant where $95 \%$ credible intervals were nonoverlapping (normalized AUC and cumulative days) or did not overlap 1 (relative effects ratios). 


\section{RESULTS}

An overview of the clinical trials included in this NMA are listed in Table 1. Included for each trial is the duration of study, baseline PASI, and the response rates for PASI 90/100 at the last timepoint of the study through Week 52 .

Normalized maximum AUC for complete (PASI 100) and almost-complete (PASI 90) skin clearance at Weeks 16 and 52 are shown in Fig. 1 . The numerically highest cumulative clinical benefits [median AUC (95\% credible interval)] for complete clearance over 52 weeks were observed for ixekizumab [0.436 (0.405, $0.467)]$, risankizumab $[0.423(0.397,0.449)]$, and brodalumab [0.378 (0.326, 0.430)] (Fig. 1). For almost-complete skin clearance, the highest cumulative benefits were observed for risankizumab $[0.671(0.645,0.697)]$, ixekizumab [0.642 $(0.610,0.673)]$, and brodalumab [0.632 (0.599, 0.656)]. Of note, ixekizumab and brodalumab, two IL-17 inhibitors, each showed significantly greater normalized AUC for almost-complete skin clearance versus secukinumab, another IL17 inhibitor $[0.578(0.559,0.597)]$, and ixekizumab also showed significantly greater normalized AUC for complete skin clearance versus secukinumab [0.324 (0.303, 0.344)]. Among IL23 inhibitors, risankizumab, showed significantly greater normalized AUC versus guselkumab for both complete and almost-complete skin clearance $[0.358(0.330,0.386)$ and 0.614 (0.587, 0.641), respectively]. Ixekizumab also showed significantly greater normalized AUC

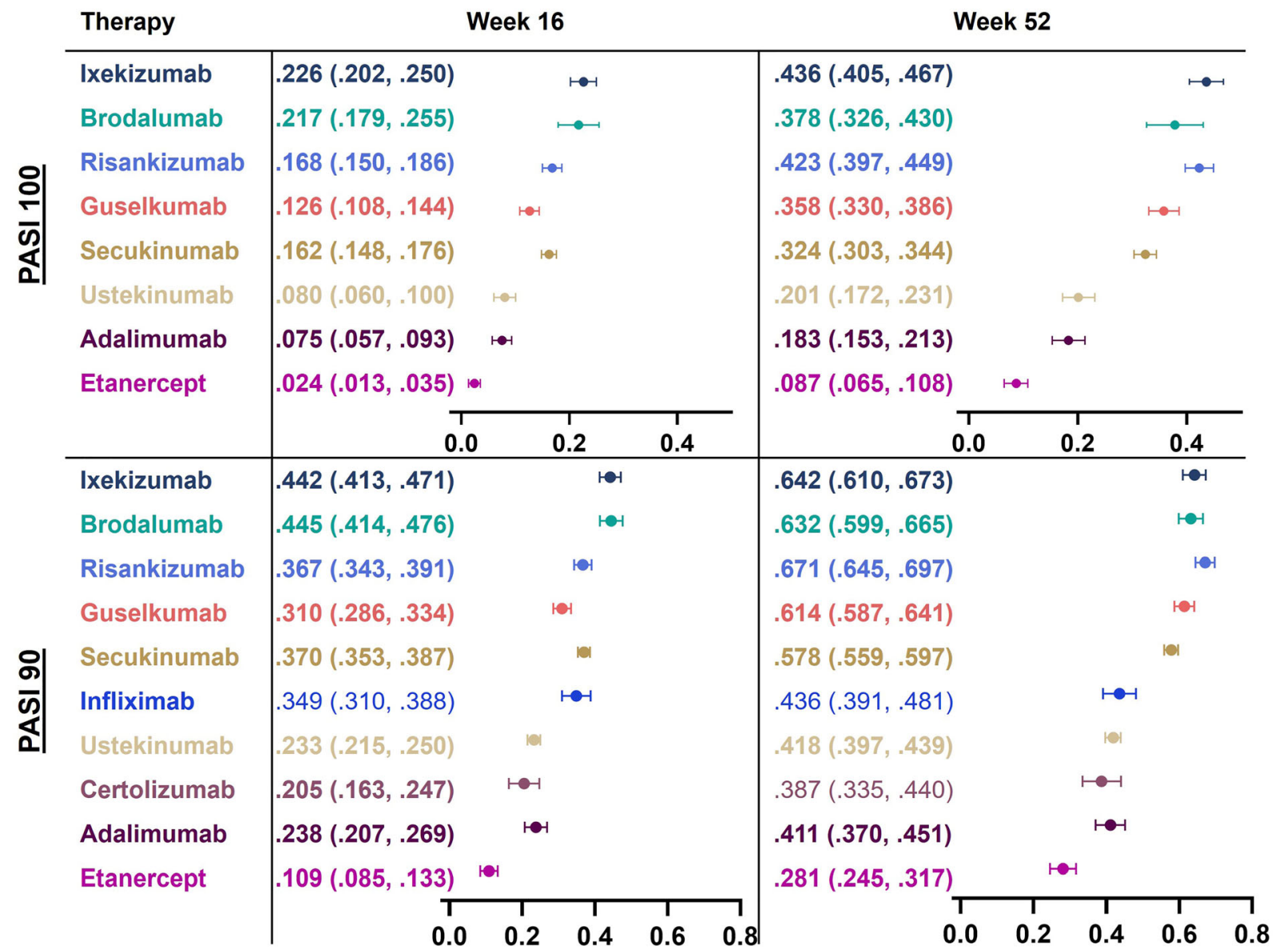

Fig. 1 Placebo-adjusted normalized maximum AUC for PASI 100 and PASI 90 at 16 and 52 Weeks. Data under the curve, PASI $100 / 90100 \%$ or $\geq 90 \%$ improvement in Psoriasis Area and Severity Index 
for complete skin clearance versus guselkumab, while risankizumab showed greater normalized AUC for complete and almost-complete skin clearance versus secukinumab. Results from the sensitivity analyses comparing absolute effects in the main NMA dataset versus 52-week data for the eight clinical trials randomized with active controls through 52 weeks were consistent with the overall findings (Table 2).

The cumulative benefits expressed as cumulative days of response over 52 weeks for PASI 100 and PASI 90 are shown in Fig. 2. Cumulative days [median days (95\% credible interval)] at PASI 100 were highest for ixekizumab [158.7 $(147.4,170.0)$ days], followed by risankizumab [154.0 (144.9, 163.4) days], and brodalumab [138.0 (118.7, 156.9) days], with a range of 31.7 $(23.7,39.7)$ to $130.7(120.5,140.9)$ days for the other biologics in this analysis. Cumulative days at PASI 90 were highest for risankizumab [249.3 $(239.5,259.2)$ days], followed by ixekizumab [238.8 (227.1, 250.8) days], and brodalumab [235.1 (222.8, 247.5) days], with a range of $107.4(93.9,120.8)$ to $228.6(218.4,238.8)$ days for the other biologics in the analysis.
The relative cumulative benefits for PASI 100 and PASI 90 over 52 weeks by ranking among the biologics is shown in Fig. 3. For PASI 100, ixekizumab showed a relative benefit that was $3 \%$ higher than risankizumab and 15\% higher than brodalumab (both not significant), and significantly higher than guselkumab (22\%) and secukinumab (35\%). For PASI 90, risankizumab showed a relative benefit that was $4 \%$ higher than ixekizumab and $6 \%$ higher than brodalumab (both not significant), and significantly higher than guselkumab (9\%) and secukinumab (16\%). All of the IL-17 and IL-23 inhibitors assessed showed significantly greater relative cumulative clinical benefit for both PASI 100 and PASI 90 at 52 weeks versus the TNF inhibitors and ustekinumab.

\section{DISCUSSION}

Many factors have to be considered when selecting the optimal therapy for psoriasis patients [24, 25]. Among them, speed, as well as magnitude and durability of response are

Table 2 Normalized AUC at week 52 for the primary analysis based on all studies and the sensitivity analysis based on eight studies

\begin{tabular}{|c|c|c|c|c|}
\hline & \multicolumn{2}{|l|}{ PASI 100} & \multicolumn{2}{|l|}{ PASI 90} \\
\hline & All studies & Eight studies & All studies & Eight studies \\
\hline Adalimumab & $0.184(0.153,0.214)$ & $0.222(0.127,0.316)$ & $0.425(0.384,0.466)$ & $0.456(0.375,0.536)$ \\
\hline Etanercept & $0.087(0.065,0.109)$ & $0.131(0.048,0.214)$ & $0.295(0.258,0.332)$ & $0.338(0.263,0.410)$ \\
\hline Ustekinumab & $0.202(0.173,0.231)$ & $0.244(0.183,0.302)$ & $0.433(0.410,0.455)$ & $0.466(0.417,0.508)$ \\
\hline Secukinumab & $0.324(0.304,0.344)$ & $0.353(0.280,0.425)$ & $0.592(0.572,0.613)$ & $0.629(0.573,0.680)$ \\
\hline Ixekizumab & $0.436(0.405,0.467)$ & $0.419(0.327,0.511)$ & $0.656(0.624,0.689)$ & $0.687(0.602,0.771)$ \\
\hline Brodalumab & $0.379(0.326,0.431)$ & $0.421(0.347,0.492)$ & $0.646(0.612,0.680)$ & $0.655(0.591,0.717)$ \\
\hline Guselkumab & $0.359(0.331,0.387)$ & $0.393(0.310,0.476)$ & $0.628(0.600,0.656)$ & $0.662(0.597,0.724)$ \\
\hline Risankizumab & $0.423(0.398,0.449)$ & $0.482(0.411,0.553)$ & $0.685(0.658,0.712)$ & $0.763(0.699,0.823)$ \\
\hline
\end{tabular}

Eight studies refers to studies randomized with active comparator arms to Week 48 or 52: AMAGINE-2 [19], AMAGINE3 [19], CLEAR [43], FIXTURE [20], IXORA-S [44], UltIMMa-1 [22], UltIMMa-2 [22], and ECLIPSE [23]

Data are shown as median (95\% credible interval). Higher value indicates greater overall time with PASI 90 or PASI 100 response

AUC area under the curve, PASI $90 \geq 90 \%$ improvement in Psoriasis Area and Severity Index, PASI $100100 \%$ improvement in Psoriasis Area and Severity Index 


\section{PASI 100}

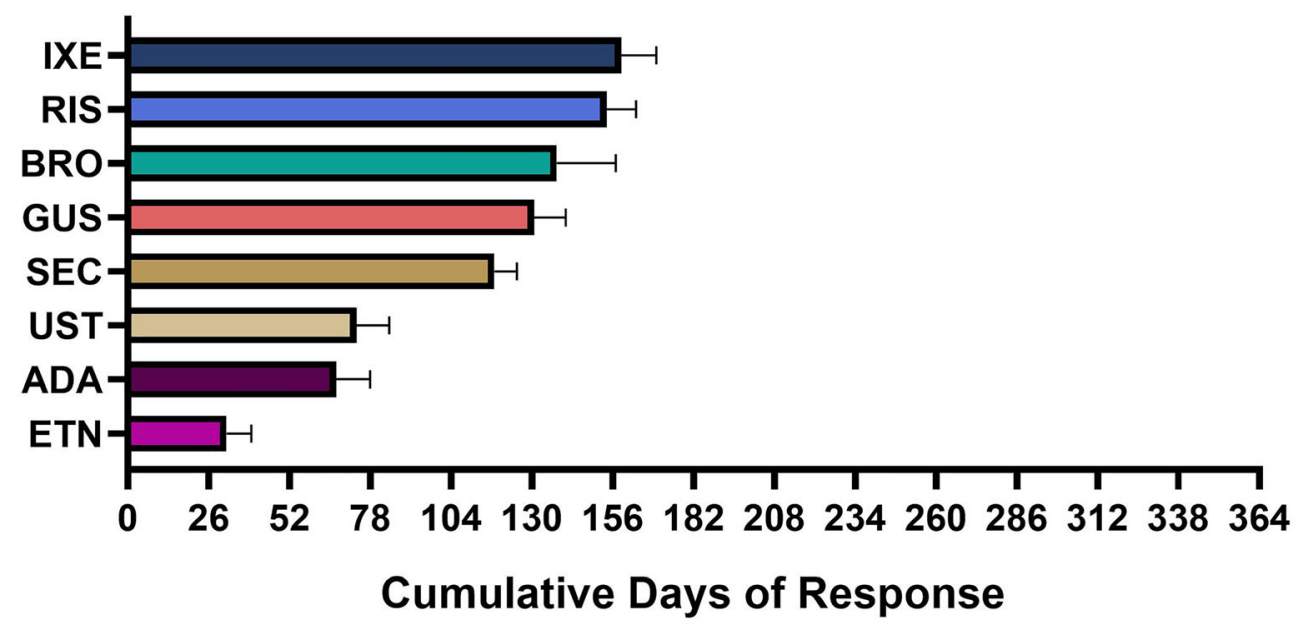

\section{PASI 90}

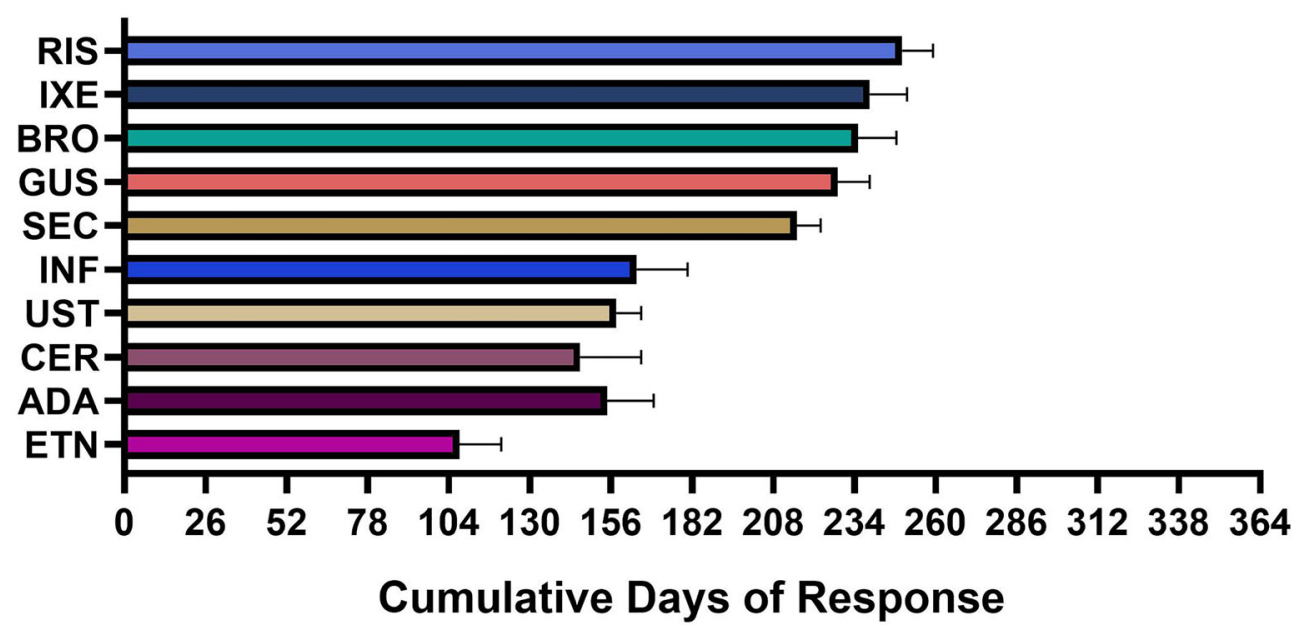

Fig. 2 Cumulative days of response at PASI 100 and PASI 90 over 52 weeks. Data displayed as 100\% maximum possible area under the curve and $95 \%$ credible interval. $A D A$ adalimumab, $B R O$ brodalumab, $C E R$ certolizumab,

important $[2-4,26,27]$. Results from our NMA suggest that ixekizumab followed by risankizumab provided the greatest cumulative benefits in complete skin clearance (PASI 100) over 52 weeks of treatment relative to guselkumab, secukinumab, and TNF inhibitors, with brodalumab intermediate between these tiers. For almost-complete skin clearance (PASI 90),
ETN etanercept, GUS guselkumab, INF infliximab, IXE ixekizumab, PASI 100/90, $100 \%$ or $\geq 90 \%$ improvement in Psoriasis Area and Severity Index, RIS risankizumab, $S E C$ secukinumab, UST ustekinumab

risankizumab and then ixekizumab, brodalumab, and guselkumab provided the highest long-term cumulative benefit. As a class, TNF inhibitors provided the lowest cumulative benefits over 1 year of treatment. Findings obtained from the sensitivity analyses without inclusion of randomized clinical trials with a placebo control arm were consistent with the main 


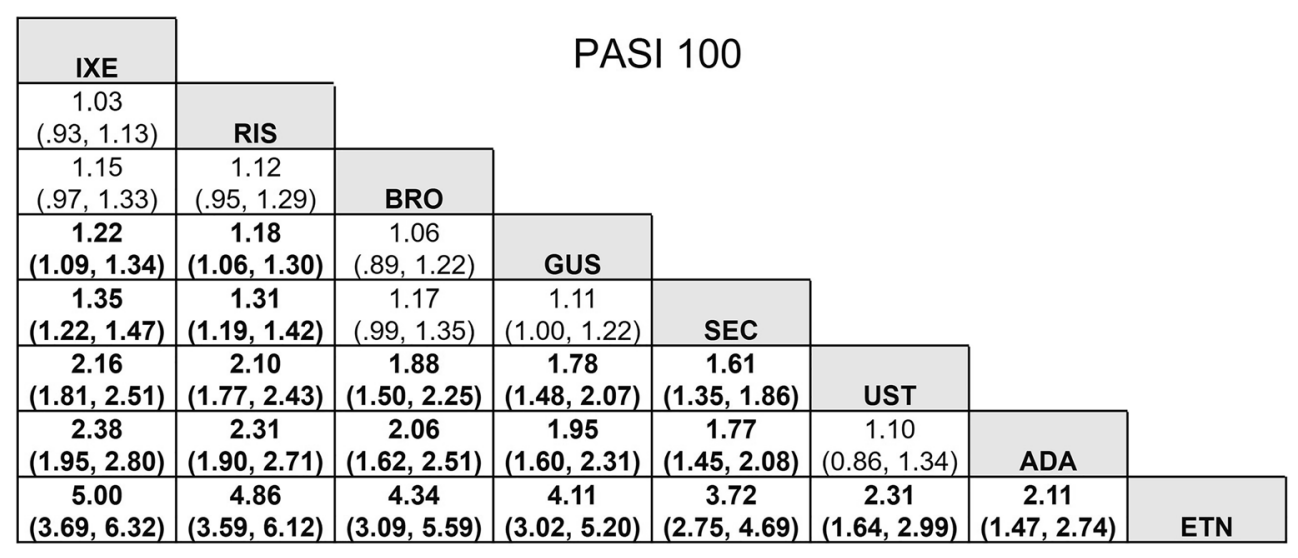

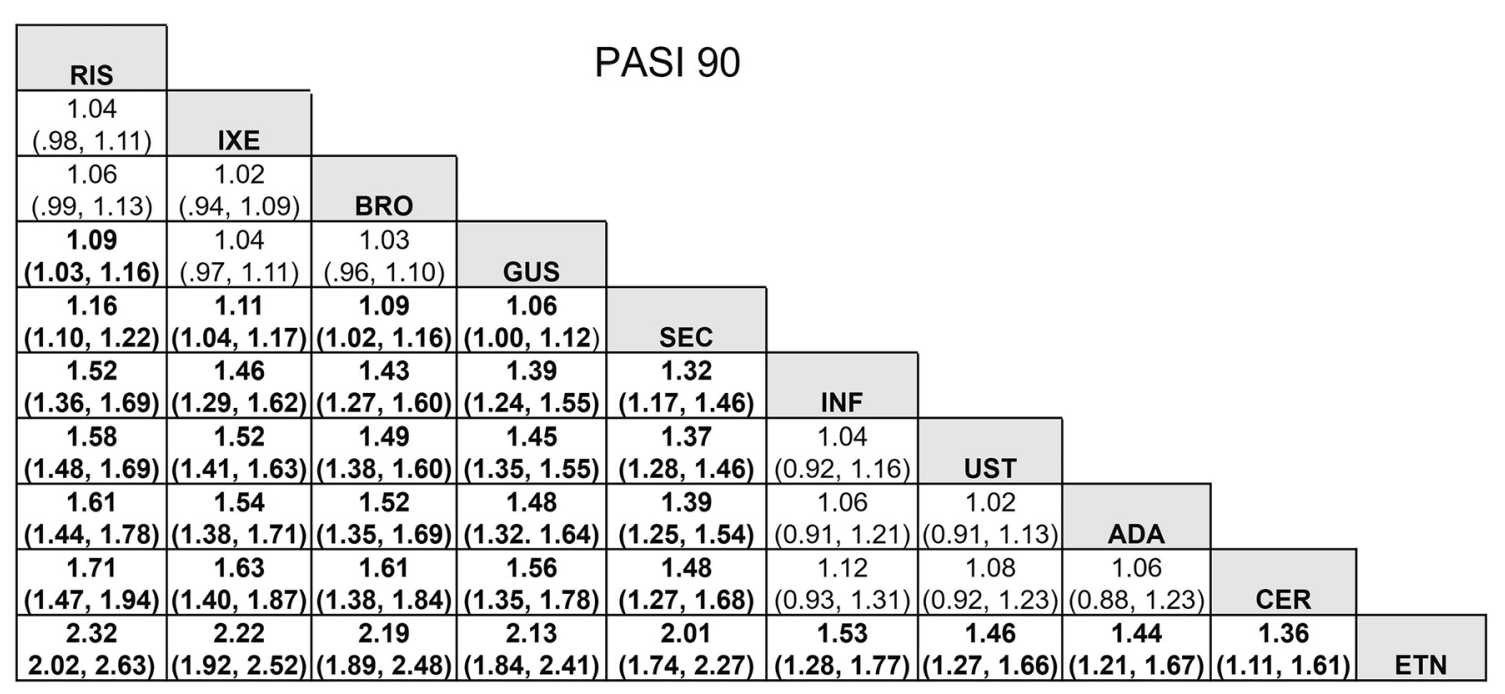

Fig. 3 Ratio of relative risk between drugs for cumulative benefit based on PASI 100 or PASI 90 at Week 52. Relative benefits calculated as relative risk between drugs for achieving PASI 100 or PASI 90 based on mean (SE) for normalized AUC. Relative effects with credible intervals not overlapping 1 are shown in bold. $A D A$

results, indicating that the data from this NMA were robust.

Patients and clinicians are facing many options for biologic treatment for moderate-tosevere psoriasis. Determining the optimal choice is difficult because many factors must be considered simultaneously. One important factor is efficacy, but efficacy comparisons can be complicated without direct head-to-head studies, since comparisons across studies may be impacted by differences in patient populations, study investigators, methods for handling adalimumab, BRO, brodalumab, CER certolizumab, ETN etanercept, GUS guselkumab, INF infliximab, IXE ixekizumab, PASI 100/90 $100 \%$ or $\geq 90 \%$ improvement in Psoriasis Area and Severity Index, RIS risankizumab, SEC secukinumab, UST ustekinumab

missing data, placebo response rates, and primary endpoint measurements (e.g., PASI 75 versus PASI 90 versus PASI 100) and timepoints (Week 12 versus Week 16 versus Week 52). These differences may be partially mitigated by network meta-analyses, which use common comparisons to normalize differences between studies. In addition, it has becoming increasingly clear that measuring efficacy responses to medications at single timepoints provides a limited view of therapeutic benefit to patients. The impact of a chronic disease such as psoriasis 
on patients is continuous, with each day being important in terms of clinical and quality of life improvements. Therefore, assessing the cumulative benefit of treatment, as estimated here using AUC analysis, takes into consideration both early rapid response and long-term maintenance of higher skin clearance levels by therapies such as ixekizumab and risankizumab, and provides a more complete picture of the efficacy of different treatments over time. In addition, estimating the cumulative days of a response provides a more stable measure than estimates of consistency or maintenance of response based on arbitrary definitions such as consecutive visits with a response.

Patients with psoriasis achieve the best quality of life with complete skin clearance (PASI 100), even when compared with almostcomplete skin clearance (PASI 90) [26-28]. A study by Dey et al. also reported greater improvements in vascular inflammation and atherosclerosis in psoriasis patients with more complete versus partial skin clearance following treatment [29]. With the emergence of biologics capable of achieving high levels of clearance, such advantages have become more evident, and treatment goals have shifted to reflect the importance of complete skin clearance [30, 31]. In the current NMA, treatment of psoriasis with ixekizumab, an IL-17A inhibitor, led to the greatest amount of time with completely clear skin over the course of 1 year, corresponding to 23 weeks (44\%) of the year. Risankizumab ranked second by this measure ( 22 weeks, $42 \%$ ), whereas TNF inhibitors as a class demonstrated the lowest amount of time with completely clear skin over 1 year. These data for ixekizumab and risankizumab reflect a combination of excellent speed of onset and durability of response over time for both drugs.

Notably, while there were small numerical differences in cumulative benefit between ixekizumab and risankizumab for both complete and almost-complete skin clearance, these did not reach statistical significance. However, for both complete and almost-complete skin clearance, ixekizumab was superior to secukinumab, and risankizumab was superior to guselkumab. Thus, while the best performing biologics in both the IL-17 and IL-23 classes offered a high level of cumulative clinical benefit, significant differences were observed between biologics within both of these drug classes. In addition, each of the IL-17 and IL-23 inhibitors were superior to TNF and IL-12/23 inhibitors, indicating significant differences in cumulative clinical benefit between first-generation biologics and all agents in the anti-IL-17 and anti-IL-23 classes.

This analysis has limitations. As in all metaanalyses, heterogeneity in patient characteristics between trials may introduce bias in the comparisons even though only phase 3 randomized clinical trials with similar inclusion and exclusion criteria were included in this study. Missing data often present challenges to comparative effectiveness studies in general, as was the case for this study in particular, which required reporting of data at all visits from baseline to Week 52 to accurately calculate cumulative benefits. Studies that only reported response rates at limited timepoints, e.g., at Weeks 12,16 , or 52 , were excluded from this analysis. In addition, we tried to eliminate data variations due to different missing data imputation methodology by selecting reports that used NRI for missing data imputation; however, a limited number of studies that used multiple imputation were included in the NMA due to data availability. Furthermore, imputation of missing values for the placebo arms beyond the $12 / 16$ week induction phases could introduce variability to the estimated placebo-adjusted normalized AUC. A random effect baseline model was used in the NMA to address the variability, and sensitivity analysis using trials without the placebo arm were conducted to assess the consistency of the findings.

Another limitation in terms of informing clinical decision making is that this analysis includes only data from randomized controlled trials. One recent real-world study comparing the effectiveness of guselkumab versus risankizumab showed comparable efficacy through 44 weeks [32, 33], albeit with a relatively small sample size, and other studies have also assessed real-world efficacy outcomes for these drugs, although also in very limited numbers of patients [34-37]. Nevertheless, the use of realworld data should be considered for future 
research when comparing outcomes across treatments.

\section{CONCLUSIONS}

In summary, this study provides clinically meaningful and relevant comparative data on biologics that reflects a combined measurement of therapeutic onset and magnitude of sustained skin clearance over time, and should better assist clinicians in their treatment choices for patients with moderate-to-severe psoriasis.

\section{ACKNOWLEDGEMENTS}

The authors would like to thank the patients and study investigators who participated in the trials.

Funding. This study was funded by Eli Lilly and Company, including payment of the Rapid Service Fee. CEMG is funded in part by the NIHR Manchester Biomedical Research Center.

Medical Writing, Editing, and Other Assistance. Medical writing assistance was provided during the preparation of this article by Gina Coudriet, PhD, Elizabeth Flate, PhD, and Thomas Melby, MS, of Syneos Health. Support for this assistance was funded by Eli Lilly and Company. Fangyu Wang, PhD, of Eli Lilly and Company supported data collection and analysis.

Authorship. All named authors meet the International Committee of Medical Journal Editors (ICMJE) criteria for authorship for this article, take responsibility for the integrity of the work as a whole, and have given their approval for this version to be published.

Author Contributions. All authors contributed to the study conception and design. Material preparation, data collection, and data analysis were performed under the direction of Baojin Zhu and Jiaying Guo. The first draft of the manuscript was written by Russel Burge and Baojin Zhu and all authors commented on previous versions of the manuscript. All authors read and approved the final manuscript.

Disclosures. Dr. Andrew Blauvelt has served as a scientific adviser and/or clinical study investigator for AbbVie, Abcentra, Aligos, Almirall, Amgen, Arcutis, Arena, Aslan, Athenex, Boehringer Ingelheim, Bristol-Myers Squibb, Dermavant, EcoR1, Eli Lilly and Company, Evommune, Forte, Galderma, Incyte, Janssen, Landos, LEO, Novartis, Pfizer, Rapt, Regeneron, Sanofi Genzyme, Sun Pharma, UCB Pharma, and Vibliome. Dr. Melinda Gooderham has served as a clinical study investigator, speaker or advisory board member for AbbVie, Amgen, Arcutis, Akros, Boehringer Ingelheim, Bristol-Myers Squibb, Celgene, Dermira, Dermavant, Eli Lilly and Company, Galderma, GSK, Incyte, Janssen, Kyowa Kirin, LEO, Medimmune, Merck, Novartis, Pfizer, Regeneron, Sanofi Genzyme, Sun Pharma, and UCB Pharma. Dr. Christopher E.M. Griffiths has received honoraria or research grants from AbbVie, Almirall, Boehringer Ingelheim, Bristol Myers Squibb, Celgene, Eli Lilly and Company, Galderma, GSK, Janssen, LEO, Pfizer, Novartis, Sandoz, Sanofi Regeneron, and UCB Pharma, and is supported in part by the Manchester NIHR Biomedical Research Centre. Dr. April W. Armstrong has served as a research investigator or consultant to LEO, AbbVie, UCB, Janssen, Eli Lilly and Company, Novartis, Ortho Dermatologics, Sun Pharma, Dermavant, BMS, Sanofi, Regeneron, Dermira, and Modmed. Baojin Zhu, Russel Burge, Gaia Gallo, Jiaying Guo, and Alyssa Garrelts were employees and shareholders of Eli Lilly and Company. Dr. Mark Lebwohl is an employee of Mount Sinai and receives research funds from: AbbVie, Amgen, Arcutis, Avotres, Boehringer Ingelheim, Dermavant Sciences, Eli Lilly and Company, Incyte, Janssen Research \& Development, LLC, Ortho Dermatologics, Regeneron, and UCB, Inc., and is a consultant for Aditum Bio, Almirall, AltruBio Inc., AnaptysBio, Arcutis, Inc., Aristea Therapeutics, Arrive Technologies, Avotres Therapeutics, BiomX, Boehringer Ingelheim, BristolMyers Squibb, Cara Therapeutics, Castle Biosciences, Corrona, Dermavant Sciences, Dr. Reddy's Laboratories, Evelo Biosciences, 
Evommune, Inc., Facilitation of International Dermatology Education, Forte Biosciences, Foundation for Research and Education in Dermatology, Helsinn Therapeutics, Hexima Ltd., LEO Pharma, Meiji Seika Pharma, Mindera, Pfizer, Seanergy, and Verrica.

Compliance with Ethics Guidelines. This article is based on previously conducted studies and does not contain any new studies with human participants or animals performed by any of the authors.

Data Availability. The datasets generated for the current study were derived from the original published reports, except for UNCOVER-3 trial, as detailed in the study methods. Data used in these analyses for the UNCOVER-3 trial are available upon request.

Open Access. This article is licensed under a Creative Commons Attribution-NonCommercial 4.0 International License, which permits any non-commercial use, sharing, adaptation, distribution and reproduction in any medium or format, as long as you give appropriate credit to the original author(s) and the source, provide a link to the Creative Commons licence, and indicate if changes were made. The images or other third party material in this article are included in the article's Creative Commons licence, unless indicated otherwise in a credit line to the material. If material is not included in the article's Creative Commons licence and your intended use is not permitted by statutory regulation or exceeds the permitted use, you will need to obtain permission directly from the copyright holder. To view a copy of this licence, visit http://creativecommons.org/licenses/by$\mathrm{nc} / 4.0 /$.

\section{REFERENCES}

1. Vanderpuye-Orgle J, Zhao Y, Lu J, Shrestha A, Sexton A, Seabury S, et al. Evaluating the economic burden of psoriasis in the United States. J Am Acad Dermatol. 2015;72(6):961-7 e5.
2. Gorelick J, Shrom D, Sikand K, Renda L, Burge R, Dworkin $\mathrm{C}$, et al. Understanding treatment preferences in patients with moderate to severe plaque psoriasis in the USA: results from a cross-sectional patient survey. Dermatol Ther (Heidelb). 2019;9(4): 785-97.

3. Carrascosa JM, de la Cueva P, Herranz P, Labandeira J, Notario J. Perception of psoriasis treatment in the outpatient setting: survey of patients and their prescribing physicians. J Dermatolog Treat. 2017;28(3):188-99.

4. Blome C, Gosau R, Radtke MA, Reich K, Rustenbach SJ, Spehr C, et al. Patient-relevant treatment goals in psoriasis. Arch Dermatol Res. 2016;308(2):69-78.

5. Augustin M. Cumulative life course impairment: identifying patients at risk. Curr Probl Dermatol. 2013;44:74-81.

6. Warren RB, Gooderham M, Burge R, Zhu B, Amato $\mathrm{D}$, Liu $\mathrm{KH}$, et al. Comparison of cumulative clinical benefits of biologics for the treatment of psoriasis over 16 weeks: results from a network meta-analysis. J Am Acad Dermatol. 2020;82(5):1138-49.

7. Armstrong AW, Feldman SR, Korman NJ, Meng X, Guana A, Nyirady J, et al. Assessing the overall benefit of a medication: cumulative benefit of secukinumab over time in patients with moderateto-severe plaque psoriasis. J Dermatolog Treat. 2017;28(3):200-5.

8. Blauvelt A, Lomaga M, Burge R, Zhu B, Shen W, Shrom D, et al. Greater cumulative benefits from ixekizumab versus ustekinumab treatment over 52 weeks for patients with moderate-to-severe psoriasis in a randomized, double-blinded phase $3 \mathrm{~b}$ clinical trial. J Dermatolog Treat. 2020;31(2):141-6.

9. Gordon KB, Blauvelt A, Papp KA, Langley RG, Luger $\mathrm{T}$, Ohtsuki $\mathrm{M}$, et al. Phase 3 trials of ixekizumab in moderate-to-severe plaque psoriasis. N Engl J Med. 2016;375(4):345-56.

10. Blauvelt A, Leonardi C, Elewski B, Crowley JJ, Guenther LC, Gooderham M, et al. A head-to-head comparison of ixekizumab vs. guselkumab in patients with moderate-to-severe plaque psoriasis: 24-week efficacy and safety results from a randomized, double-blinded trial. Br J Dermatol. 2020.

11. Reich K, Papp KA, Blauvelt A, Tyring SK, Sinclair R, Thaci $\mathrm{D}$, et al. Tildrakizumab versus placebo or etanercept for chronic plaque psoriasis (reSURFACE 1 and reSURFACE 2): results from two randomised controlled, phase 3 trials. Lancet. 2017;390(10091): 276-88.

12. Dias S, Welton NJ, Sutton AJ, Caldwell DM, Lu G, Ades AE. Evidence synthesis for decision making 4: 
inconsistency in networks of evidence based on randomized controlled trials. Med Decis Making. 2013;33(5):641-56.

13. Dias S, Welton NJ, Sutton AJ, Ades AE. NICE DSU Technical Support Document 2: A generalised linear modelling framework for pairwise and network meta-analysis of randomised controlled trials. 2011; last updated September 2016.

14. Brooks SP, Gelman A. General methods for monitoring convergence of iterative simulations. J Comput Graph Stat. 1998;7:434-55.

15. R_Core_Team. R: A language and environment for statistical computing. Vienna, Austria. R Foundation for Statistical Computing; 2020.

16. Gottlieb AB, Blauvelt A, Thaci D, Leonardi CL, Poulin Y, Drew J, et al. Certolizumab pegol for the treatment of chronic plaque psoriasis: Results through 48 weeks from 2 phase 3, multicenter, randomized, double-blinded, placebo-controlled studies (CIMPASI-1 and CIMPASI-2). J Am Acad Dermatol. 2018;79(2):302-14 e6.

17. Bagel J, Blauvelt A, Nia J, Hashim P, Patekar M, de Vera A, et al. Secukinumab maintains superiority over ustekinumab in clearing skin and improving quality of life in patients with moderate to severe plaque psoriasis: 52-week results from a doubleblind phase $3 \mathrm{~b}$ trial (CLARITY). J Eur Acad Dermatol Venereol JEADV. 2021;35(1):135-42.

18. Blauvelt A, Reich K, Tsai TF, Tyring S, Vanaclocha F, Kingo K, et al. Secukinumab is superior to ustekinumab in clearing skin of subjects with moderateto-severe plaque psoriasis up to 1 year: Results from the CLEAR study. J Am Acad Dermatol. 2017;76(1): 60-9 e9.

19. Lebwohl M, Strober B, Menter A, Gordon K, Weglowska J, Puig L, et al. Phase 3 studies comparing brodalumab with ustekinumab in psoriasis. N Engl J Med. 2015;373(14):1318-28.

20. Langley RG, Elewski BE, Lebwohl M, Reich K, Griffiths $\mathrm{CE}$, Papp $\mathrm{K}$, et al. Secukinumab in plaque psoriasis-results of two phase 3 trials. N Engl J Med. 2014;371(4):326-38.

21. Paul C, Griffiths CEM, van de Kerkhof PCM, Puig L, Dutronc Y, Henneges C, et al. Ixekizumab provides superior efficacy compared with ustekinumab over 52 weeks of treatment: results from IXORA-S, a phase 3 study. J Am Acad Dermatol. 2019;80(1):70-9 e3.

22. Gordon KB, Strober B, Lebwohl M, Augustin M, Blauvelt A, Poulin Y, et al. Efficacy and safety of risankizumab in moderate-to-severe plaque psoriasis (UltIMMa-1 and UltIMMa-2): results from two double-blind, randomised, placebo-controlled and ustekinumab-controlled phase 3 trials. Lancet. 2018;392(10148):650-61.

23. Reich K, Armstrong AW, Langley RG, Flavin S, Randazzo B, Li S, et al. Guselkumab versus secukinumab for the treatment of moderate-to-severe psoriasis (ECLIPSE): results from a phase 3, randomised controlled trial. Lancet. 2019;394(10201):831-9.

24. Kaushik SB, Lebwohl MG. Psoriasis: which therapy for which patient: focus on special populations and chronic infections. J Am Acad Dermatol. 2019;80(1):43-53.

25. Kaushik SB, Lebwohl MG. Psoriasis: Which therapy for which patient: psoriasis comorbidities and preferred systemic agents. J Am Acad Dermatol. 2019;80(1):27-40.

26. Revicki DA, Willian MK, Menter A, Saurat JH, Harnam N, Kaul M. Relationship between clinical response to therapy and health-related quality of life outcomes in patients with moderate to severe plaque psoriasis. Dermatology. 2008;216(3):260-70.

27. Viswanathan HN, Chau D, Milmont CE, Yang W, Erondu N, Revicki DA, et al. Total skin clearance results in improvements in health-related quality of life and reduced symptom severity among patients with moderate to severe psoriasis. J Dermatol Treat. 2015;26(3):235-9.

28. Strober B, Papp KA, Lebwohl M, Reich K, Paul C, Blauvelt A, et al. Clinical meaningfulness of complete skin clearance in psoriasis. J Am Acad Dermatol. 2016;75(1):77-82 e7.

29. Dey AK, Joshi AA, Chaturvedi A, Lerman JB, Aberra TM, Rodante JA, et al. Association between skin and aortic vascular inflammation in patients with psoriasis: a case-cohort study using positron emission tomography/computed tomography. JAMA Cardiol. 2017;2(9):1013-8.

30. Gisondi P, Talamonti M, Chiricozzi A, Piaserico S, Amerio P, Balato A, et al. Treat-to-target approach for the management of patients with moderate-tosevere plaque psoriasis: consensus recommendations. Dermatol Ther (Heidelb). 2021;11(1):235-52.

31. Mahil SK, Wilson N, Dand N, Reynolds NJ, Griffiths CEM, Emsley R, et al. Psoriasis treat to target: defining outcomes in psoriasis using data from a real-world, population-based cohort study (the British Association of Dermatologists Biologics and Immunomodulators Register, BADBIR). Br J Dermatol. 2020;182(5):1158-66.

32. Ruggiero A, Fabbrocini G, Cinelli E, Megna M. Guselkumab and risankizumab for psoriasis: a 44-week indirect real-life comparison. J Am Acad Dermatol. 2021;85(4):1028-30. 
33. Ruggiero A, Fabbrocini G, Cinelli E, Megna M. Real world practice indirect comparison between guselkumab and risankizumab: results from an Italian retrospective study. Dermatol Ther. 2022;35(1):e15214.

34. Megna M, Fabbrocini G, Cinelli E, Camela E, Ruggiero A. Guselkumab in moderate to severe psoriasis in routine clinical care: an Italian 44-week real-life experience. J Dermatol Treat. 2020; p. 1-5.

35. Megna M, Cinelli E, Gallo L, Camela E, Ruggiero A, Fabbrocini G. Risankizumab in real life: preliminary results of efficacy and safety in psoriasis during a 16-week period. Arch Dermatol Res. 2021. https:// doi.org/10.1007/s00403-021-02200-7.

36. Megna M, Fabbrocini G, Ruggiero A, Cinelli E. Efficacy and safety of risankizumab in psoriasis patients who failed anti-IL-17, anti-12/23 and/or anti IL-23: Preliminary data of a real-life 16-week retrospective study. Dermatol Ther. 2020;33(6):e14144.

37. Ruggiero A, Fabbrocini G, Cinelli E, Ocampo Garza SS, Camela E, Megna M. Anti-interleukin-23 for psoriasis in elderly patients: guselkumab, risankizumab and tildrakizumab in real-world practice. Clin Exp Dermatol. 2021. https://doi.org/10.1111/ced.14979.

38. Reich K, Nestle FO, Papp K, Ortonne JP, Evans R, Guzzo $C$, et al. Infliximab induction and maintenance therapy for moderate-to-severe psoriasis: a phase III, multicentre, double-blind trial. Lancet. 2005;366(9494):1367-74.

39. Blauvelt A, Prinz JC, Gottlieb AB, Kingo K, Sofen H, Ruer-Mulard M, et al. Secukinumab administration by pre-filled syringe: efficacy, safety and usability results from a randomized controlled trial in psoriasis (FEATURE). Br J Dermatol. 2015;172(2):484-93.
40. Warren RB, Blauvelt A, Poulin Y, Beeck S, Kelly M, $\mathrm{Wu} \mathrm{T}$, et al. Efficacy and safety of risankizumab vs secukinumab in patients with moderate-to-severe plaque psoriasis (IMMerge): results from a phase III, randomized, open-label, efficacy-assessor-blinded clinical trial. Br J Dermatol. 2021;184(1):50-9.

41. Lacour JP, Paul C, Jazayeri S, Papanastasiou P, Xu C, Nyirady J, et al. Secukinumab administration by autoinjector maintains reduction of plaque psoriasis severity over 52 weeks: results of the randomized controlled JUNCTURE trial. J Eur Acad Dermatol Venereol JEADV. 2017;31(5):847-56.

42. Blauvelt A, Gooderham M, Iversen L, Ball S, Zhang L, Agada NO, et al. Efficacy and safety of ixekizumab for the treatment of moderate-to-severe plaque psoriasis: results through 108 weeks of a randomized, controlled phase 3 clinical trial (UNCOVER-3). J Am Acad Dermatol. 2017;77(5): 855-62.

43. Blauvelt A, Papp KA, Griffiths CE, Randazzo B, Wasfi Y, Shen YK, et al. Efficacy and safety of guselkumab, an anti-interleukin-23 monoclonal antibody, compared with adalimumab for the continuous treatment of patients with moderate to severe psoriasis: results from the phase III, doubleblinded, placebo- and active comparator-controlled VOYAGE 1 trial. J Am Acad Dermatol. 2017;76(3): 405-17.

44. Reich K, Pinter A, Lacour JP, Ferrandiz C, Micali G, French LE, et al. Comparison of ixekizumab with ustekinumab in moderate-to-severe psoriasis: 24-week results from IXORA-S, a phase III study. Br J Dermatol. 2017;177(4):1014-23. 